\title{
Urinary proteome profiling for children with autism using data-independent acquisition proteomics
}

\author{
Wenshu Meng, Yuhang Huan, Youhe Gao \\ Gene Engineering Drug and Biotechnology Beijing Key Laboratory, College of Life Sciences, Beijing Normal University, Beijing, China \\ Contributions: (I) Conception and design: Y Gao; W Meng; (II) Administrative support: Y Gao; (III) Provision of study materials or patients: Y Gao; \\ W Meng; (IV) Collection and assembly of data: W Meng; Y Huan; (V) Data analysis and interpretation: All authors; (VI) Manuscript writing: All \\ authors; (VII) Final approval of manuscript: All authors. \\ Correspondence to: Youhe Gao. Beijing Key Laboratory of Gene Engineering Drug and Biotechnology, College of Life Sciences, Beijing Normal \\ University, No. 19 XinJieKouWai Street, HaiDian District, Beijing, China. Email: gaoyouhe@bnu.edu.cn.
}

\begin{abstract}
Background: Autism is a complex neurodevelopmental disorder. Objective and reliable biomarkers are crucial for the clinical diagnosis of autism. Urine can accumulate early changes of the whole body and is a sensitive source for disease biomarkers.

Methods: The data-independent acquisition (DIA) strategy was used to identify differential proteins in the urinary proteome between autistic and non-autistic children aged 3-7 years. Receiver operating characteristic (ROC) curves were developed to evaluate the diagnostic performance of differential proteins.

Results: A total of 118 differential proteins were identified in the urine between autistic and non-autistic children, of which 18 proteins were reported to be related to autism. Randomized grouping statistical analysis indicated that $91.5 \%$ of the differential proteins were reliable. Functional analysis revealed that some differential proteins were associated with axonal guidance signaling, endocannabinoid developing neuron pathway, synaptic long-term depression, agrin interactions at neuromuscular junction, phosphatase and tensin homolog deleted on chromosome 10 (PTEN) signaling and synaptogenesis signaling pathway. The combination of cadherin-related family member 5 (CDHR5) and vacuolar protein sorting-associated protein 4B (VPS4B) showed the best discriminative performance between autistic and non-autistic children with an area under the curve (AUC) value of 0.987.
\end{abstract}

Conclusions: The urinary proteome could distinguish between autistic children and non-autistic children. This study will provide a promising approach for future biomarker research of neuropsychiatric disorders.

Keywords: Autism; urine; proteome; biomarker; diagnosis

Submitted Apr 28, 2021. Accepted for publication Jun 21, 2021.

doi: $10.21037 /$ tp-21-193

View this article at: https://dx.doi.org/10.21037/tp-21-193

\section{Introduction}

Autism spectrum disorder (ASD) is a complex neurodevelopmental disorder characterized by difficulties in social interaction and limited repetitive behaviors, interests, or activities (1). The incidence of autism has continued to increase over the past two decades, with the number of patients with autism as high as $1 \%$ to $2.5 \%$ of the total population and a male/female ratio of 4:1 (2). Autism usually occurs at an early stage and is a lifelong developmental disorder that places a heavy burden on families and public health.

The etiology and pathological mechanism of autism are uncertain, which brings challenges to its diagnosis and intervention. There is currently no effective treatment for ASD, but some studies have found that behavioral 


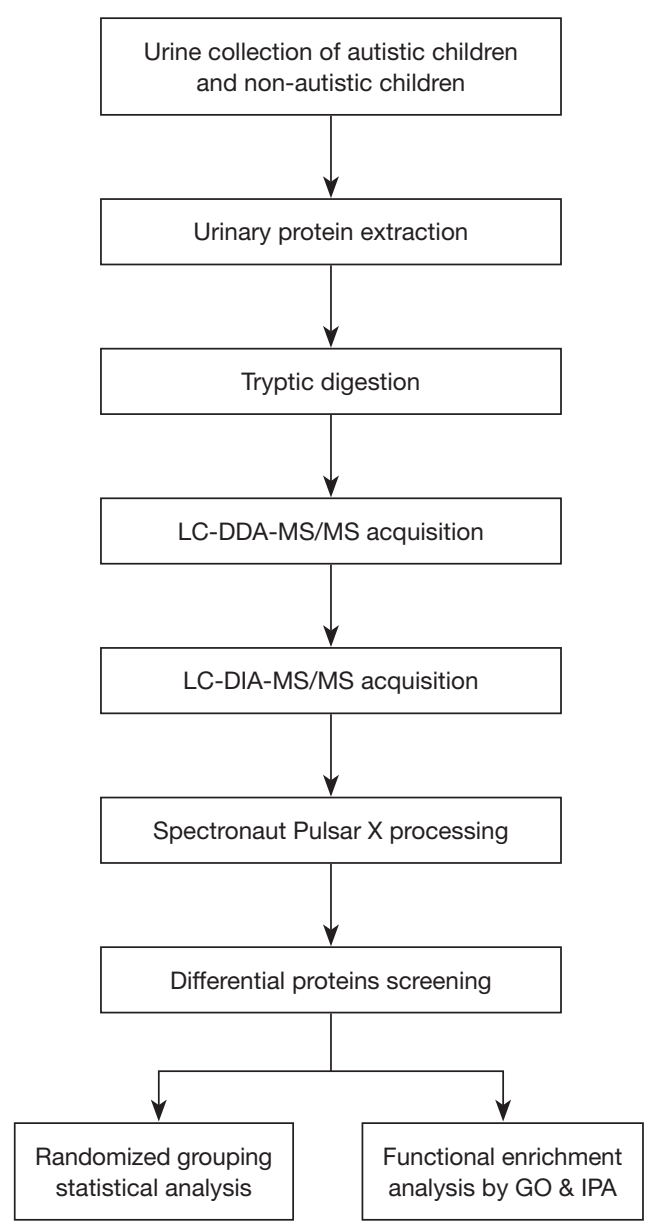

Figure 1 The workflow of urine proteome analysis in children with autism. DDA, data-dependent acquisition; DIA, data-independent acquisition; GO, gene ontology; IPA, ingenuity pathway analysis; LC-MS/MS, liquid chromatography couple with tandem mass spectrometry.

interventions for autistic children can effectively alleviate their symptoms at the early stage (3). Therefore, the early diagnosis is crucial for autism. The clinical diagnosis of autism mainly relies on behavioral and cognitive assessment according to the criteria in the diagnostic and statistical manual of mental disorders, which is certain subjective. Hence, the objective and reliable biomarkers are needed for the diagnosis of autism.

Previous proteomic studies on biomarkers and pathogenetic mechanisms of ASD have focused on blood, saliva and brain tissues (4-8). However, only a few studies have used urine. Urine is a sensitive source for diseases biomarkers. Without the control of homeostatic mechanisms, urine can accumulate early changes of the whole body (9). In addition, urine collection is simple and non-invasive. There are several clinical studies showed that urine could reflect pathological changes of various diseases involving brain and nervous system, such as Alzheimer's disease (10), familial Parkinson's disease (11), pediatric medulloblastoma (12), and gliomas (13). However, for neuropsychiatric disorders with abnormal social behaviors such as ASD, it is unknown whether urine can show differences.

In this study, the data-independent acquisition (DIA) strategy was used to identify differential proteins in the urinary proteome between autistic and non-autistic children aged 3-7 years. This study aims to investigate whether the urinary proteome can distinguish between autistic children and non-autistic children. The workflow of this study is presented in Figure 1.

We present the following article in accordance with the MDAR reporting checklist (available at https://dx.doi. org/10.21037/tp-21-193).

\section{Methods}

\section{Urine sample collection}

In this study, urine samples from 18 autistic children aged 3-7 years from the Fengtai District Sunshine Angel Special Training Center in Beijing and 6 non-autistic children aged 3-6 years from Beijing Normal University were collected (Table S1). All ASD patients were diagnosed by child neuropsychiatrists according to criteria defined in the Diagnostic and Statistical Manual of Mental DisordersFifth Edition (DSM-V). The study was conducted in accordance with the Declaration of Helsinki (as revised in 2013) for research on human participants, and the study protocols were approved by the Institutional Review Board at Beijing Normal University (ICBIR_A_0098_006). Written informed consent was obtained from the parents of all participants.

\section{Urinary protein extraction and tryptic digestion}

Urine samples were centrifuged at 12,000 $\times \mathrm{g}$ for $40 \mathrm{~min}$ at $4{ }^{\circ} \mathrm{C}$ to remove impurities and large cell debris. The supernatants were precipitated with three volumes of ethanol at $-20^{\circ} \mathrm{C}$ overnight and then centrifuged at $12,000 \times \mathrm{g}$ for $30 \mathrm{~min}$ at $4{ }^{\circ} \mathrm{C}$. The precipitate was resuspended in lysis buffer [ $8 \mathrm{~mol} / \mathrm{L}$ urea, $2 \mathrm{~mol} / \mathrm{L}$ thiourea, $50 \mathrm{mmol} / \mathrm{L}$ Tris, and $25 \mathrm{mmol} / \mathrm{L}$ dithiothreitol (DTT)]. The Bradford assay was 
used to measure the protein concentration of each sample.

The urinary proteins were digested using the filter-aided sample preparation (FASP) method (14). A total of 100 $\mu \mathrm{g}$ protein of each sample was loaded onto a $10 \mathrm{kDa}$ filter device (Pall, Port Washington, NY, USA) and washed twice with UA (8 mol/L urea, $0.1 \mathrm{~mol} / \mathrm{L}$ Tris-HCl, $\mathrm{pH} 8.5)$ and $25 \mathrm{mmol} / \mathrm{L} \mathrm{NH}_{4} \mathrm{HCO}_{3}$. The samples were reduced with 20 mmol/L DTT (Sigma, St. Louis, USA) at $37^{\circ} \mathrm{C}$ for $1 \mathrm{~h}$ and then alkylated with $50 \mathrm{mmol} / \mathrm{L}$ iodoacetamide (IAA, Sigma, St. Louis, USA) in the dark for $40 \mathrm{~min}$. After washing once with UA and twice with $25 \mathrm{mmol} / \mathrm{L} \mathrm{NH}_{4} \mathrm{HCO}_{3}$, the proteins were digested with trypsin (enzyme-to-protein ratio of $1: 50)$ at $37^{\circ} \mathrm{C}$ overnight. The peptide mixtures were desalted using Oasis HLB cartridges (Waters, Milford, MA, USA) and then dried by vacuum evaporation.

\section{High-pH reversed-phased peptide fractionation}

The peptide samples were dissolved in $0.1 \%$ formic acid and diluted to $0.5 \mu \mathrm{g} / \mu \mathrm{L}$. For the generation of spectral library, $96 \mu \mathrm{g}$ of pooled peptides from $4 \mu \mathrm{g}$ of each sample was fractionated using a high-pH reversed-phased peptide fractionation kit (catalog number: 84868, Thermo, USA). According to the manufacturer's instructions, 10 fractionated samples were obtained and were dried by vacuum evaporation. Then, 10 fractionated samples were dissolved in $20 \mu \mathrm{L}$ of $0.1 \%$ formic acid. One microgram of each fraction was loaded for liquid chromatography couple with tandem mass spectrometry (LC-MS/MS) analysis in data-dependent acquisition (DDA) mode.

\section{LC-MS/MS analysis}

An EASY-nLC 1200 chromatography system (Thermo Fisher Scientific, Waltham, MA, USA) and an Orbitrap Fusion Lumos Tribrid mass spectrometer (Thermo Fisher Scientific, Waltham, MA, USA) were used for mass spectrometry acquisition and analysis. The iRT reagent (Biognosys, Switzerland) was spiked at a concentration of $1: 10 \mathrm{v} / \mathrm{v}$ into all urinary samples for calibration of the retention time of the extracted peptide peaks. All peptide samples were loaded on a trap column $(75 \mu \mathrm{m} \times 2 \mathrm{~cm}, 3 \mu \mathrm{m}, \mathrm{C} 18,100 \AA)$ and a reverse-phase analysis column $(75 \mu \mathrm{m} \times 25 \mathrm{~cm}, 2 \mu \mathrm{m}, \mathrm{C} 18,100 \AA)$. The eluted gradient was $4-35 \%$ buffer B $(0.1 \%$ formic acid in $80 \%$ acetonitrile) at a flow rate of $300 \mathrm{~nL} / \mathrm{min}$ for $90 \mathrm{~min}$.

In DDA mode, the parameters were set as follows: the full scan from 350 to $1,500 \mathrm{~m} / \mathrm{z}$ with resolution at 120,000 and MS/MS scan with resolution at 30,000 in Orbitrap; the $30 \%$ higher-energy collisional dissociation (HCD) energy; the maximum injection time of $45 \mathrm{~ms}$.

In DIA mode, $1 \mu \mathrm{g}$ of each sample was analyzed with twice replicates. The DIA method with 36 variable windows was set for DIA acquisition (Table S2). The parameters were set as follows: the full scan from 350 to $1,500 \mathrm{~m} / \mathrm{z}$ with resolution at 60,000; the DIA scan from 200 to $2,000 \mathrm{~m} / \mathrm{z}$ with resolution of 30,000 ; the $32 \%$ HCD energy; and the maximum injection time of $100 \mathrm{~ms}$. A quality control (QC) sample of the mixture from each sample was analyzed in DIA acquisition after every four samples.

\section{Spectral library generation and data analysis}

The DDA data of 10 fractions were processed using Proteome Discoverer software (version 2.1, Thermo Scientific) and searched against the Swiss-Prot Human database (released in 2018, including 20,346 sequences) appended with the iRT peptide sequence. The search parameters were set as follows: two missed trypsin cleavage sites were allowed; the parent ion mass tolerances were set to $10 \mathrm{ppm}$; the fragment ion mass tolerances were set to $0.02 \mathrm{Da}$; the carbamidomethyl of cysteine was set as a fixed modification; and the oxidation of methionine was set as a variable modification. The false discovery rate (FDR) of proteins was less than $1 \%$. A total of 2,184 protein groups, 11,518 peptide groups and 59,341 peptide spectrum matches were identified. The search result was used to set the variable windows for DIA mode. For the generation of spectral library, the DDA raw files were imported to Spectronaut Pulsar X software (Biognosys, Switzerland). All DIA raw files were processed using Spectronaut Plusar X software with default setting. All results were filtered by a $Q$ value cutoff of 0.01 . The protein identification was based on two unique peptides.

\section{Statistical analysis}

A comparison of proteins between autistic and nonautistic group was conducted using independent samples $t$-test. Group differences resulting in $\mathrm{P}<0.05$ were considered statistically significant. Differential proteins were screened with the following criteria: fold change in increasing group $\geq 1.5$ and in decreasing group $\leq 0.67$, $\mathrm{P}<0.01$. Receiver operating characteristic (ROC) analysis were performed for individual proteins and protein combinations using Metaboanalyst software (https:// 
A

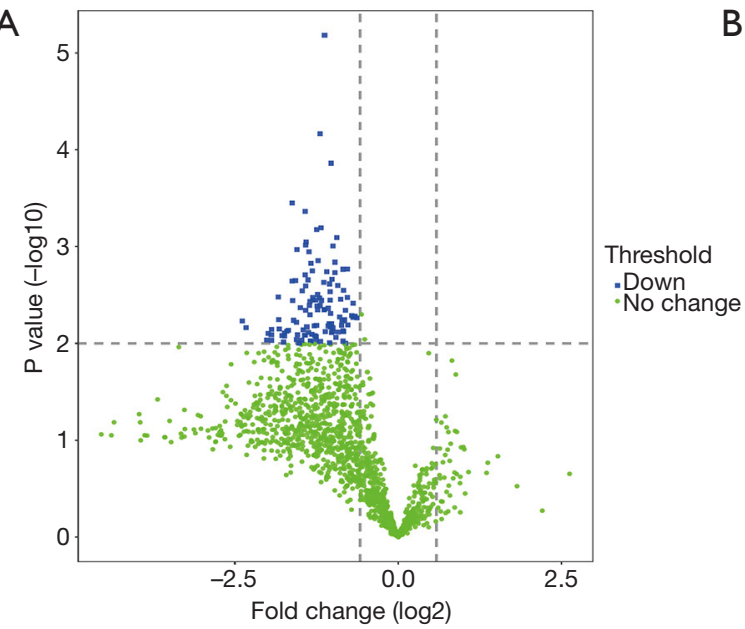

B

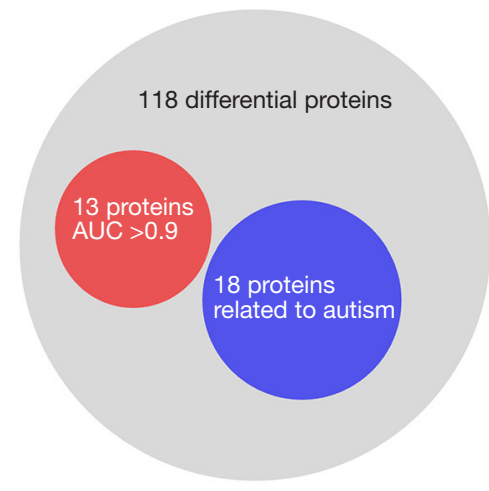

Figure 2 Differential proteins analysis by comparing autistic urine samples with non-autistic urine samples. (A) Volcano plots of differential proteins; (B) Veen diagram of 118 differential proteins, 18 proteins related to autism, and the top 13 differential proteins with AUC values (AUC >0.9). AUC, area under the curve.

www.metaboanalyst.ca).

\section{Functional enrichment analysis}

Functional annotation of differential proteins was performed using DAVID 6.8 (https://david.ncifcrf.gov) (15) and ingenuity pathway analysis (IPA) software (Ingenuity Systems, Mountain View, CA, USA), including biological process, cellular component, molecular function and pathways. The threshold of significance was set at a $\mathrm{P}<0.05$.

\section{Results}

\section{Identification of differential proteins in ASD urinary proteome}

To investigate differences between autistic and non-autistic children, 24 urinary samples from 18 autistic children and 6 non-autistic children were analyzed after proteolysis by LC-DIA-MS/MS. A total of 1,631 protein groups were identified in this study. A QC sample of the mixture from each sample was analyzed after every four samples. The $95 \%$ of the quantile of coefficient of variation $(\mathrm{CV})$ value of the $\mathrm{QC}$ was 0.51 , and proteins with $\mathrm{CV}>0.51$ were considered outliers. A total of 1,511 proteins with the CV below 0.51 were for subsequent analysis, and the identification and quantification details are listed in online table (available at https://cdn.amegroups.cn/static/public/ tp-21-193-1.pdf). Among them, 118 differential proteins were identified between the autistic and non-autistic groups (fold change $\geq 1.5$ or $\leq 0.67, \mathrm{P}<0.01$ ), the volcano plot of differential proteins is shown in Figure $2 A$. The details of the differential proteins are listed in Table 1.

\section{Randomized grouping statistical analysis}

Given that the number of proteomic features identified in the samples was higher than the number of samples, the differences between two groups might be randomly generated. A randomized grouping statistical analysis strategy was developed to confirm whether these differential proteins were caused by disease. Twenty-four samples from the autism $(n=18)$ and control groups $(n=6)$ were randomly divided into two groups and the same criteria were used to screen differential proteins. In a total of $134,596\left(C_{24}^{6}\right)$ combinations, the average number of differential proteins was 10 . These results showed that only 10 differential proteins could be generated randomly, further indicating that $91.5 \%$ of the differential proteins were reliable.

\section{ROC curve analysis}

To evaluate the diagnostic performance of differential proteins between autistic and non-autistic children, ROC curves were performed for individual proteins and protein combinations. Among 118 differential proteins, 13 proteins (CDHR5, VPS4B, NICA, LEG1, ARL3, MANBA, VATG1, CO5A2, CHM1B, CDC42, NRP1, F13B, INAR1) 
Table 1 The differential proteins identified in urine samples between autistic and healthy children

\begin{tabular}{|c|c|c|c|c|}
\hline Accession & Description & Ratio of $\mathrm{ASD} / \mathrm{HC}$ & $P$ value & Reference \\
\hline P54652 & Heat shock-related $70 \mathrm{kDa}$ protein 2 & 0.6356 & 0.0052 & - \\
\hline O00461 & Golgi integral membrane protein 4 & 0.6234 & 0.0054 & - \\
\hline P07204 & Thrombomodulin & 0.6227 & 0.0038 & - \\
\hline Q99816 & Tumor susceptibility gene 101 protein & 0.5869 & 0.0065 & - \\
\hline Q9H0E2 & Toll-interacting protein & 0.5856 & 0.0034 & - \\
\hline Q9UN37 & Vacuolar protein sorting-associated protein $4 \mathrm{~A}$ & 0.5852 & 0.0017 & - \\
\hline P61204 & ADP-ribosylation factor 3 & 0.5725 & 0.0046 & - \\
\hline Q8WV92 & MIT domain-containing protein 1 & 0.5622 & 0.0028 & - \\
\hline Q8NHP8 & Putative phospholipase B-like 2 & 0.5602 & 0.0075 & - \\
\hline Q04756 & Hepatocyte growth factor activator & 0.5586 & 0.0017 & - \\
\hline Q8TAB3 & Protocadherin-19 & 0.5583 & 0.0095 & - \\
\hline Q9HD42 & Charged multivesicular body protein 1a & 0.5578 & 0.0074 & - \\
\hline P27105 & Stomatin & 0.5542 & 0.0059 & - \\
\hline P08758 & Annexin A5 & 0.5494 & 0.0065 & - \\
\hline 000560 & Syntenin-1 & 0.5453 & 0.0035 & - \\
\hline O95971 & CD160 antigen & 0.5132 & 0.0019 & - \\
\hline Q7LBR1 & Charged multivesicular body protein $1 \mathrm{~b}$ & 0.5131 & 0.0014 & - \\
\hline P51148 & Ras-related protein Rab-5C & 0.5026 & 0.0010 & - \\
\hline Q16348 & Solute carrier family 15 member 2 & 0.5023 & 0.0075 & - \\
\hline P54707 & Potassium-transporting ATPase alpha chain 2 & 0.5007 & 0.0069 & - \\
\hline P14314 & Glucosidase 2 subunit beta & 0.4976 & 0.0022 & - \\
\hline P01033 & Metalloproteinase inhibitor 1 & 0.4935 & 0.0077 & - \\
\hline P18510 & Interleukin-1 receptor antagonist protein & 0.4928 & 0.0063 & $(16)$ \\
\hline Q99538 & Legumain & 0.4921 & 0.0068 & - \\
\hline 075348 & V-type proton ATPase subunit G 1 & 0.4911 & 0.0001 & - \\
\hline Q14108 & Lysosome membrane protein 2 & 0.4893 & 0.0067 & - \\
\hline
\end{tabular}

Table 1 (continued) 
Table 1 (continued)

\begin{tabular}{|c|c|c|c|c|}
\hline Accession & Description & Ratio of $\mathrm{ASD} / \mathrm{HC}$ & $P$ value & Reference \\
\hline Q92542 & Nicastrin & 0.4875 & 0.0036 & $(17)$ \\
\hline P0DJD8 & Pepsin A-3 & 0.4873 & 0.0029 & - \\
\hline P62834 & Ras-related protein Rap-1A & 0.4844 & 0.0099 & - \\
\hline Q8WUM4 & Programmed cell death 6-interacting protein & 0.4810 & 0.0063 & - \\
\hline Q5VW32 & BRO1 domain-containing protein BROX & 0.4764 & 0.0066 & - \\
\hline P46109 & Crk-like protein & 0.4763 & 0.0043 & - \\
\hline P07711 & Procathepsin L & 0.4691 & 0.0018 & (18) \\
\hline Q96SM3 & Probable carboxypeptidase $\mathrm{X} 1$ & 0.4575 & 0.0045 & - \\
\hline Q9Y3E7 & Charged multivesicular body protein 3 & 0.4569 & 0.0045 & - \\
\hline Q8IX04 & Ubiquitin-conjugating enzyme E2 variant 3 & 0.4545 & 0.0023 & - \\
\hline 060939 & Sodium channel subunit beta- 2 & 0.4432 & 0.0036 & - \\
\hline Q6P1N0 & Coiled-coil and $\mathrm{C} 2$ domain-containing protein $1 \mathrm{~A}$ & 0.4425 & 0.0006 & (19) \\
\hline P15311 & Ezrin & 0.4384 & 0.0095 & - \\
\hline Q9Y6N7 & Roundabout homolog 1 & 0.4366 & 0.0041 & (20) \\
\hline O75351 & Vacuolar protein sorting-associated protein 4B & 0.4364 & 0.0001 & - \\
\hline Q9H3G5 & Probable serine carboxypeptidase CPVL & 0.4225 & 0.0007 & - \\
\hline Q9BYH1 & Seizure 6-like protein & 0.4207 & 0.0065 & $(22)$ \\
\hline Q5JXA9 & Signal-regulatory protein beta- 2 & 0.4194 & 0.0093 & - \\
\hline Q9UBD6 & Ammonium transporter Rh type C & 0.4194 & 0.0085 & - \\
\hline P10912 & Growth hormone receptor & 0.4168 & 0.0036 & - \\
\hline P09936 & Ubiquitin carboxyl-terminal hydrolase isozyme L1 & 0.4139 & 0.0083 & (23) \\
\hline P02749 & Beta-2-glycoprotein 1 & 0.4112 & 0.0066 & $(24)$ \\
\hline P09543 & 2',3'-cyclic-nucleotide 3'-phosphodiesterase & 0.4051 & 0.0036 & - \\
\hline P36405 & ADP-ribosylation factor-like protein 3 & 0.4047 & 0.0034 & - \\
\hline P08754 & Guanine nucleotide-binding protein $G(i)$ subunit alpha & 0.4034 & 0.0018 & - \\
\hline Q9BRG1 & Vacuolar protein-sorting-associated protein 25 & 0.4010 & 0.0080 & - \\
\hline
\end{tabular}

Table 1 (continued) 
Table 1 (continued)

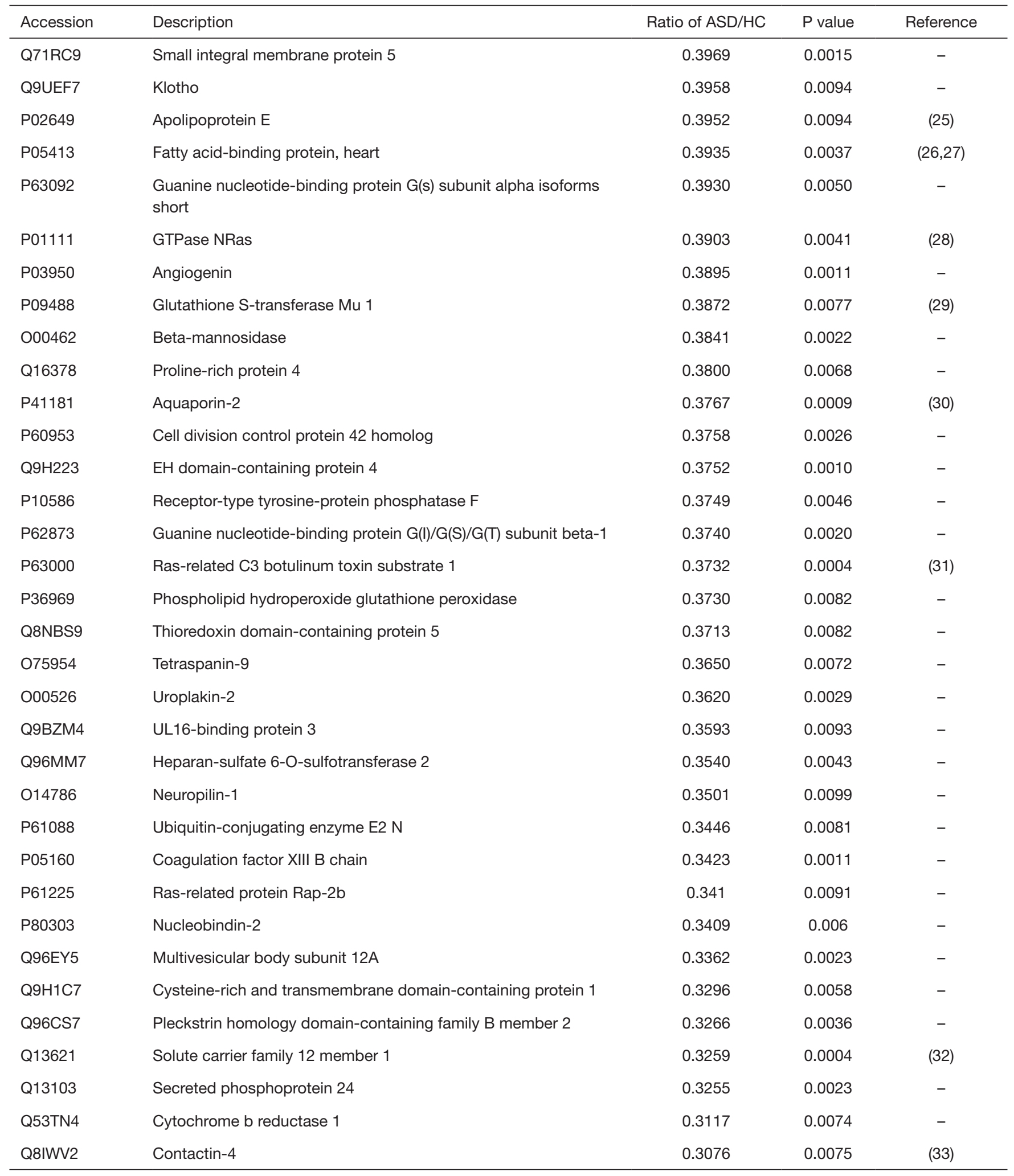

Table 1 (continued) 
Table 1 (continued)

\begin{tabular}{|c|c|c|c|c|}
\hline Accession & Description & Ratio of $\mathrm{ASD} / \mathrm{HC}$ & $P$ value & Reference \\
\hline P17181 & Interferon alpha/beta receptor 1 & 0.2997 & 0.0084 & - \\
\hline P50897 & Palmitoyl-protein thioesterase 1 & 0.2964 & 0.0097 & - \\
\hline 060613 & Selenoprotein F & 0.2927 & 0.0083 & - \\
\hline P63096 & Guanine nucleotide-binding protein G(i) subunit alpha-1 & 0.2813 & 0.0057 & - \\
\hline P05997 & Collagen alpha-2(V) chain & 0.2801 & 0.0033 & - \\
\hline Q9ULZ9 & Matrix metalloproteinase-17 & 0.2616 & 0.0072 & - \\
\hline P24821 & Tenascin & 0.2610 & 0.0093 & (34) \\
\hline P21796 & Voltage-dependent anion-selective channel protein 1 & 0.2480 & 0.0092 & - \\
\hline P09382 & Galectin-1 & 0.1988 & 0.0069 & - \\
\hline P02511 & Alpha-crystallin B chain & 0.1910 & 0.0059 & - \\
\hline
\end{tabular}

ASD, autism spectrum disorder; HC, healthy control. Ratio of ASD/HC represents each protein abundance in the ASD group divide by protein abundance in the $\mathrm{HC}$ group.

showed the good discriminative performance between autistic and non-autistic children (AUC >0.9) (Figure 2B, Table 2). As shown in Figure 3, the combination of CDHR5 and VPS4B showed an AUC of 0.987, which was higher than that of the individual protein. Thus, these differential proteins and protein panels could be potential diagnostic biomarkers for autism.

\section{Function analysis of the differential proteins}

Functional annotation of 118 differential proteins was performed by DAVID. The differential proteins were classified into biological process, cellular component, and molecular function. In the biological process category, 62 items were significantly enriched (Table S3), of which representative biological processes are presented in Figure $4 A$. These differential proteins were involved in viral budding via host endosomal sorting complex required for transport (ESCRT) complex, multivesicular body assembly, autophagy, small GTPase mediated signal transduction, Ras protein signal transduction, axon guidance, chemical synaptic transmission, and negative regulation of neuron death. In the cellular component category, the majority of differential proteins came from extracellular exosomes (Figure 4B). In the molecular function category, GTPase activity, GTP binding, signal transducer activity and protein homodimerization activity were overrepresented (Figure 4C).

To identify the major biological pathways of differential proteins, IPA software was performed for canonical pathways and network analysis. A total of 206 items were significantly enriched (online table available at https:// cdn.amegroups.cn/static/public/tp-21-193-2.pdf), of which representative pathways are presented in Figure 4D. Axonal guidance signaling, endocannabinoid developing neuron pathway, STAT3 pathway, phosphatase and tensin homolog deleted on chromosome 10 (PTEN) signaling, synaptogenesis signaling pathway, synaptic long-term depression, and PI3K/AKT signaling were overrepresented. In addition, IPA network analysis revealed that a total of 25 differential proteins were involved in the top regulator effect network "cell-to-cell signaling and interaction, cellular movement, hematological system development and function" with score 47 (Figure 5).

\section{Discussion}

In this study, urine proteome in children with autism was analyzed by DIA proteomics, and 118 differential proteins 
Table 2 The top 13 differential proteins with AUC values

\begin{tabular}{lll}
\hline Accession & Description & AUC \\
\hline Q9HBB8 & Cadherin-related family member 5 & 0.98148 \\
O75351 & Vacuolar protein sorting-associated protein 4B & 0.96296 \\
Q92542 & Nicastrin & 0.93519 \\
P09382 & Galectin-1 & 0.93519 \\
P36405 & ADP-ribosylation factor-like protein 3 & 0.92593 \\
O00462 & Beta-mannosidase & 0.92593 \\
O75348 & V-type proton ATPase subunit G 1 & 0.91667 \\
P05997 & Collagen alpha-2(V) chain & 0.91667 \\
Q7LBR1 & Charged multivesicular body protein 1b & 0.90741 \\
P60953 & Cell division control protein 42 homolog & 0.90741 \\
O14786 & Neuropilin-1 & 0.90741 \\
P05160 & Coagulation factor XIII B chain & 0.90741 \\
P17181 & Interferon alpha/beta receptor 1 & 0.90741
\end{tabular}

AUC, area under the curve.

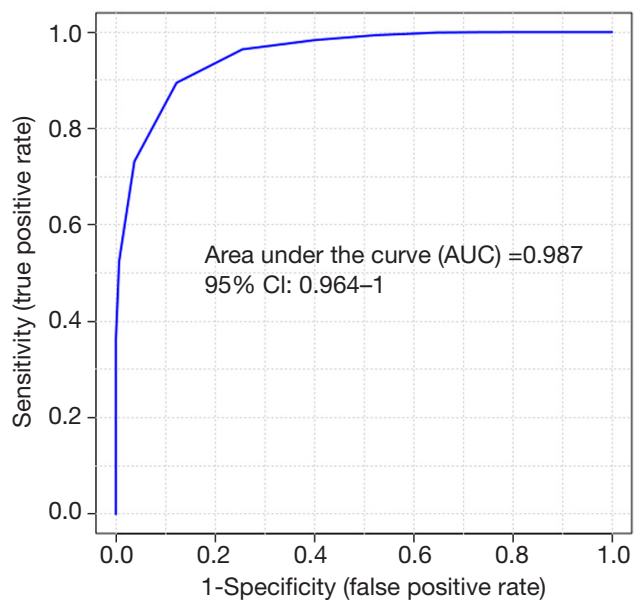

Figure 3 ROC curve analysis of the combination of CDHR5 and VPS4B. ROC, receiver operating characteristic; CDHR5, cadherin-related family member 5; VPS4B, vacuolar protein sorting-associated protein 4B; CI, confidence interval.

were identified between autistic and non-autistic children. Among them, 18 proteins have been reported to be related to autism (Figure 2B). For example, interleukin 1 receptor antagonist protein (IL1RA) is an anti-inflammatory cytokine that was downregulated in the serum of autistic patients (16). Nicastrin (NCSTN) plays an important role in the regulation of short-term and long-term synaptic plasticity (17). Cathepsin L1 (CATL1) stimulates neuronal axon growth (18). CC2D1A (19) has been reported to be as candidate genes for autism. The abnormality of ROBO may cause autism by interfering with the serotonergic system or interfering with neurodevelopment (20). SNAP25 was reported to be involved in autism, seizures, and intellectual disability (21), and SNAP23 was downregulated in this study. SEZ6L (22) is a candidate gene for autism. Low levels of ubiquitin carboxy-terminal hydrolase isoenzyme L1 (UCHL1) is associated with ubiquitination interference in autism (23). Beta-2-glycoprotein $1(\mathrm{APOH})$ was reported to be elevated in the plasma of patients with autism compared with that of control subjects (24). APOE hypermethylation is associated with ASD in the Chinese population (25). The abnormal expression of $F A B P 7$ and FABP5 genes in individuals with autism was found, and $F A B P 3$ was downregulated in the urine of ASD patients, which plays a key role in cognition and emotional behavior $(26,27)$. NRAS (28) is a candidate gene of ASD. GSTM1 genotype may serve as a moderator of the effect of some prenatal factors on the risk of ASD (29). The expression of AQP4 in the brains of autistic patients was reported to be decreased (30). We found that AQP2 were downregulated in the urine of ASD patients. RAC1 stimulates the initiation and elongation of dendrites, Rac1/PAK/LIMK signaling 
A

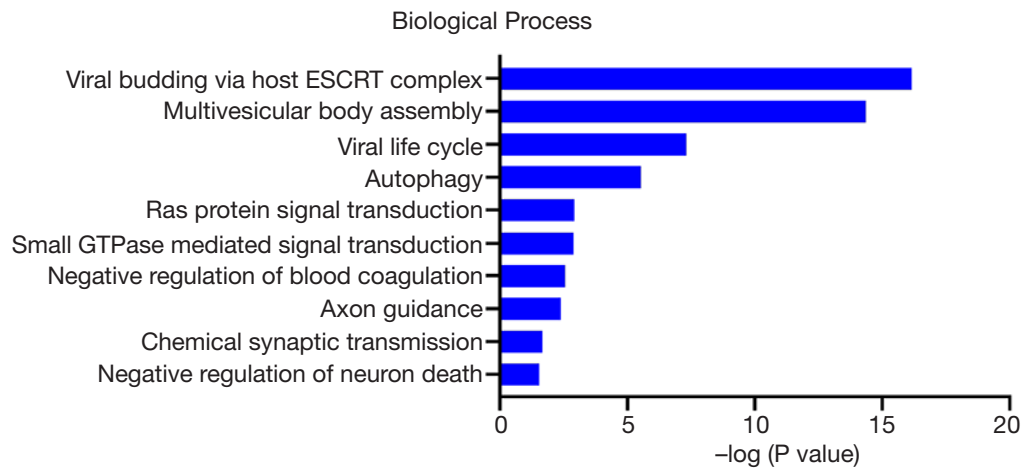

B

Cellular component

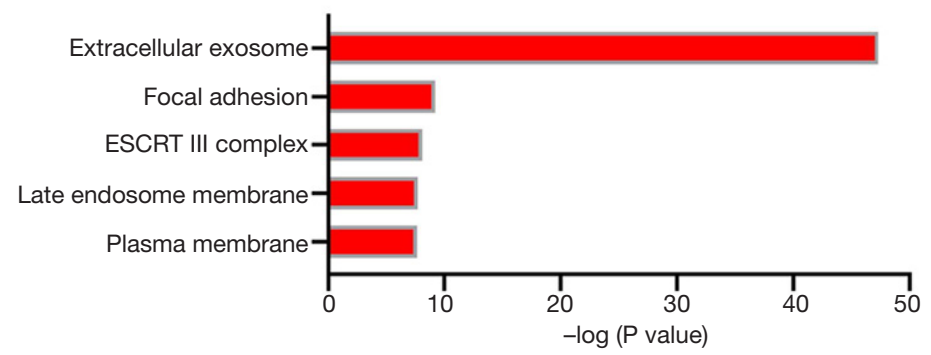

C

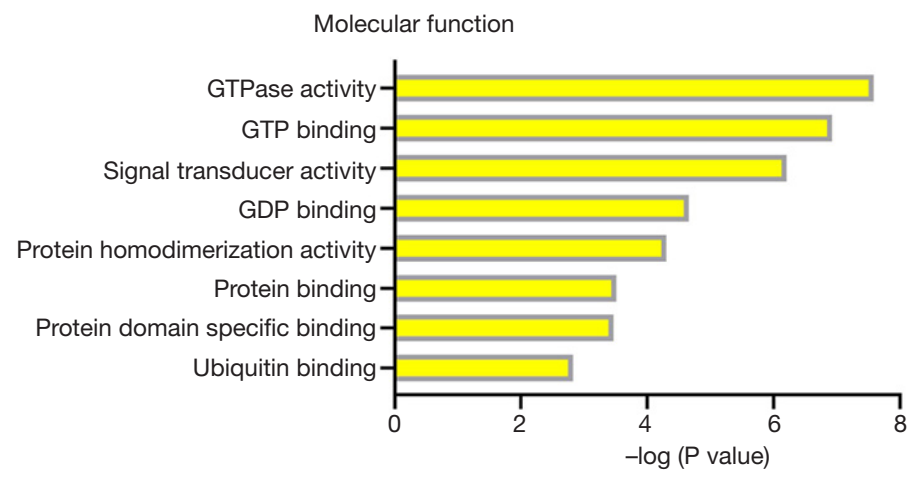

D

Pathways

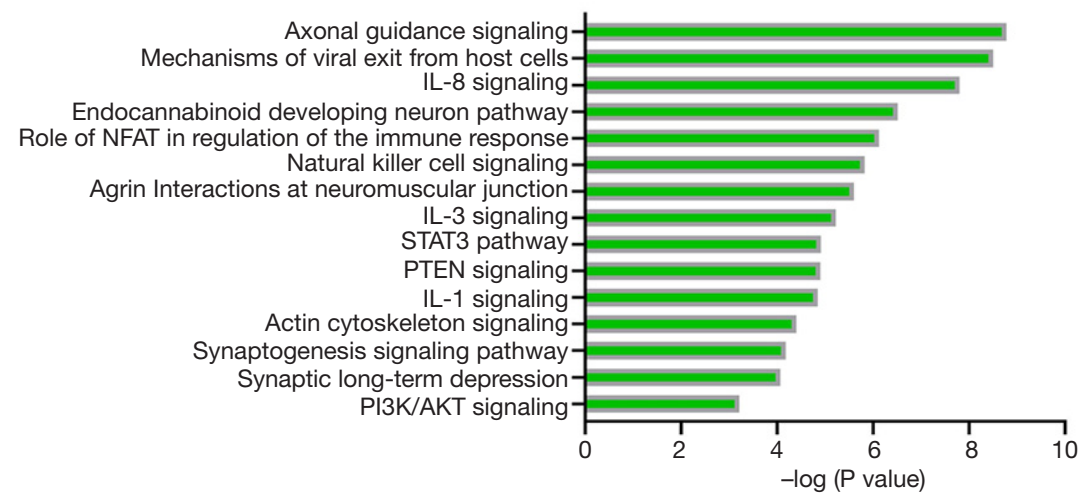

Figure 4 Functional analysis of differential proteins. (A) Biological process; (B) cellular component; (C) molecular function; (D) pathways. ESCRT, endosomal sorting complex required for transport; GTPase, guanosine triphosphate hydrolase; GDP, guanosine diphosphate; GTP, guanosine triphosphate; NFAT, nuclear factor of activated T cells; STAT3, signal transducer and activator of transcription 3; PTEN, phosphatase and tensin homolog deleted on chromosome 10; IL-8, interleukin 8; IL-3, interleukin 3; IL-1, interleukin 1; P13K/AKT, phosphatidylinositol-3 kinase/cellular homolog of the viral oncogene v-Akt. 


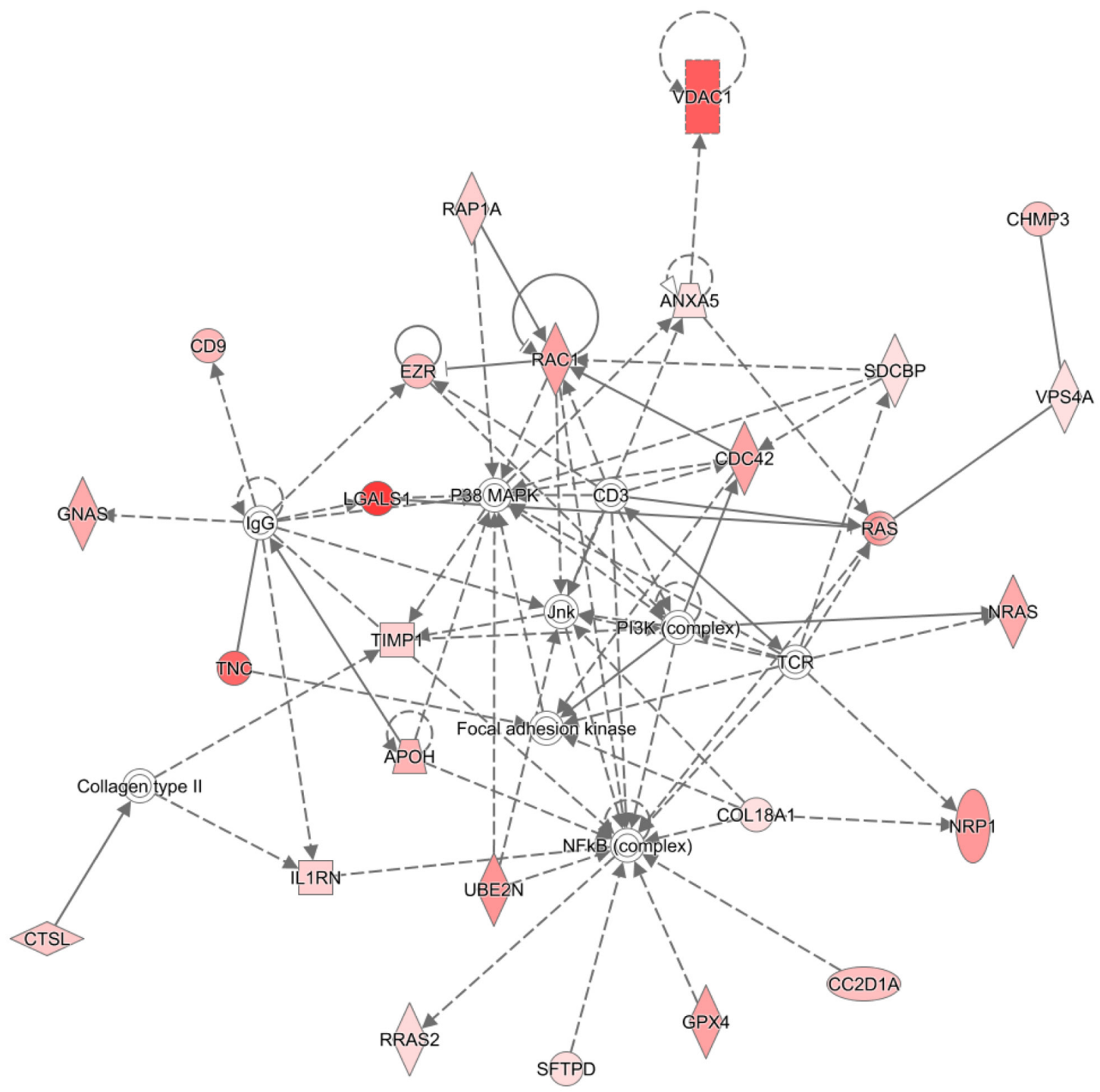

Figure 5 IPA revealed that the top regulator effect network. Red indicates down-regulated proteins in this study. IPA, ingenuity pathway analysis.

promotes actin filament assembly, and actin dysregulation is a pathophysiological mechanism of autism (31). Bumetanide administration can improve the symptoms of autism (32). We found that bumetanide-sensitive sodium-(potassium)chloride cotransporter 2 (SLC12A1) was downregulated in urine. CNTN4 plays an important role in the formation, maintenance, and plasticity of neuronal networks and disruption of contactin 4 has been reported in ASD patients (33). The mutations in the tenascin $\mathrm{C}$ (TNC) gene could cause sensory impairment in ASD (34). Although some differential proteins have not been reported to be related to autism, they also might serve as candidate urinary biomarkers for autism.

In addition, some important pathways were associated with autism. For example, changes in axonal microstructure are considered to be the basis of the cognitive performance of people with autism (35), several differential proteins were involved in axonal guidance signaling. Moreover, the endogenous cannabinoid system is involved in regulating many cellular functions and molecular pathways in autism, such as unbalanced glutamate and gamma-aminobutyric acid (GABA) and glutamate energy transmission, and 
disorders of the endogenous cannabinoid system may play an important role in the pathophysiology of autism $(36,37)$. Dysfunction of PTEN signaling may also be combined with changes in other autism-related genes or pathways to influence social behavior (38). Multiple susceptibility genes of autism encode synaptic-related proteins and affect the formation, elimination, transmission and plasticity of synapses (39), 9 proteins (APOE, CDC42, CRKL, NRAS, RAB5C, RAC1, RAP1A, RAP2B, RRAS2) were involved in synaptogenesis signaling pathway and 7 proteins (GNAI1, GNAI3, GNAS, NRAS, RAP1A, RAP2B, RRAS2) were involved in synaptic long-term depression. A large amount of evidence suggests that inflammation may be involved in the pathophysiological process of autism, manifested as a change in proinflammatory cytokine signals (40) and several inflammation-related signals were enriched in this study, such as IL-8 and IL-3 signaling. Thus, urinary proteins might reflect the pathophysiological process of autism and provide new targets for the intervention for autism.

Although autism is a heterogeneous neurological developmental disorder with multiple etiologies, subtypes and developmental trajectories, the urinary proteome between autistic group and non-autistic group showed clear differences, suggesting that autism might have a limited number of common biological pathways (41) or the ASD patients who contributed urine samples in this study might happen to be of similar subtypes.

This preliminary study has some limitations worth noting. First, the number of participants enrolled was limited. Secondly, the subtypes of children with autism in this study was not clear, and different subtypes may have different biomarkers, so whether our findings may be extended to other subtypes of autism is uncertain. Furthermore, whether these candidate urinary biomarkers can be applicable to earlier-age autistic children is unknown. Therefore, a large number of ASD patients with earlier ages and multiple subtypes from multicenter should be considered in future studies. Despite limitations of the study, our results demonstrate that ASD can be reflected in the urine, suggesting that urine proteome is a promising approach for diagnosis of ASD.

\section{Conclusions}

The urinary proteome could distinguish between autistic children and non-autistic children. This study will provide a promising approach for future biomarker research of neuropsychiatric disorders.

\section{Acknowledgments}

Funding: This work was supported by the National Key Research and Development Program of China (2018YFC0910202, 2016YFC1306300); the Fundamental Research Funds for the Central Universities (2020KJZX002); the Beijing Natural Science Foundation (7172076); the Beijing Cooperative Construction Project (110651103); the Beijing Normal University (11100704); and the Peking Union Medical College Hospital (20162.27). The funders had no role in study design, data collection and analysis, decision to publish, or preparation of the manuscript.

\section{Footnote}

Reporting Checklist: The authors have completed the MDAR reporting checklist. Available at https://dx.doi. org/10.21037/tp-21-193

Data Sharing Statement: Available at https://dx.doi. org/10.21037/tp-21-193

Peer Review File: Available at https://dx.doi.org/10.21037/ tp-21-193

Conflicts of Interest: All authors have completed the ICMJE uniform disclosure form (available at https://dx.doi. org/10.21037/tp-21-193). The authors have no conflicts of interest to declare.

Ethical Statement: The authors are accountable for all aspects of the work in ensuring that questions related to the accuracy or integrity of any part of the work are appropriately investigated and resolved. The study was conducted in accordance with the Declaration of Helsinki (as revised in 2013) for research on human participants, and the study protocols were approved by the Institutional Review Board at Beijing Normal University (ICBIR_A_0098_006). Written informed consent was obtained from the parents of all participants.

Open Access Statement: This is an Open Access article distributed in accordance with the Creative Commons Attribution-NonCommercial-NoDerivs 4.0 International License (CC BY-NC-ND 4.0), which permits the noncommercial replication and distribution of the article with the strict proviso that no changes or edits are made and the 
original work is properly cited (including links to both the formal publication through the relevant DOI and the license). See: https://creativecommons.org/licenses/by-nc-nd/4.0/.

\section{References}

1. Lai MC, Lombardo MV, Baron-Cohen S. Autism. Lancet 2014;383:896-910.

2. Lyall K, Croen L, Daniels J, et al. The Changing Epidemiology of Autism Spectrum Disorders. Annu Rev Public Health 2017;38:81-102.

3. Fernell E, Eriksson MA, Gillberg C. Early diagnosis of autism and impact on prognosis: a narrative review. Clin Epidemiol 2013;5:33-43.

4. Shen L, Zhang K, Feng C, et al. iTRAQ-Based Proteomic Analysis Reveals Protein Profile in Plasma from Children with Autism. Proteomics Clin Appl 2018;12:e1700085.

5. Corbett BA, Kantor AB, Schulman H, et al. A proteomic study of serum from children with autism showing differential expression of apolipoproteins and complement proteins. Mol Psychiatry 2007;12:292-306.

6. Ngounou Wetie AG, Wormwood KL, Russell S, et al. A Pilot Proteomic Analysis of Salivary Biomarkers in Autism Spectrum Disorder. Autism Res 2015;8:338-50.

7. Amal H, Barak B, Bhat V, et al. Shank3 mutation in a mouse model of autism leads to changes in the S-nitroso-proteome and affects key proteins involved in vesicle release and synaptic function. Mol Psychiatry 2020;25:1835-48.

8. Abraham J, Szoko N, Natowicz MR. Proteomic Investigations of Autism Spectrum Disorder: Past Findings, Current Challenges, and Future Prospects. Adv Exp Med Biol 2019;1118:235-52.

9. Gao Y. Urine-an untapped goldmine for biomarker discovery? Sci China Life Sci 2013;56:1145-6.

10. Watanabe Y, Hirao Y, Kasuga K, et al. Molecular Network Analysis of the Urinary Proteome of Alzheimer's Disease Patients. Dement Geriatr Cogn Dis Extra 2019;9:53-65.

11. Virreira Winter S, Karayel O, Strauss MT, et al. Urinary proteome profiling for stratifying patients with familial Parkinson's disease. EMBO Mol Med 2021;13:e13257.

12. Hao X, Guo Z, Sun H, et al. Urinary protein biomarkers for pediatric medulloblastoma. J Proteomics 2020;225:103832.

13. Wu J, Zhang J, Wei J, et al. Urinary biomarker discovery in gliomas using mass spectrometry-based clinical proteomics. Chin Neurosurg J 2020;6:11.

14. Wiśniewski JR, Zougman A, Nagaraj N, et al. Universal sample preparation method for proteome analysis. Nat Methods 2009;6:359-62.

15. Huang da W, Sherman BT, Lempicki RA. Systematic and integrative analysis of large gene lists using DAVID bioinformatics resources. Nat Protoc 2009;4:44-57.

16. Saghazadeh A, Ataeinia B, Keynejad K, et al. Antiinflammatory cytokines in autism spectrum disorders: A systematic review and meta-analysis. Cytokine 2019;123:154740.

17. Lee SH, Sharma M, Südhof TC, et al. Synaptic function of nicastrin in hippocampal neurons. Proc Natl Acad Sci U S A 2014;111:8973-8.

18. Tohda C, Tohda M. Extracellular cathepsin L stimulates axonal growth in neurons. BMC Res Notes 2017;10:613.

19. Sener EF, Cikılı Uytun M, Korkmaz Bayramov K, et al. The roles of CC2D1A and HTR1A gene expressions in autism spectrum disorders. Metab Brain Dis 2016;31:613-9.

20. Anitha A, Nakamura K, Yamada K, et al. Genetic analyses of roundabout (ROBO) axon guidance receptors in autism. Am J Med Genet B Neuropsychiatr Genet 2008;147B:1019-27.

21. Najera K, Fagan BM, Thompson PM. SNAP-25 in Major Psychiatric Disorders: A Review. Neuroscience 2019;420:79-85.

22. Chapman NH, Nato AQ Jr, Bernier R, et al. Whole exome sequencing in extended families with autism spectrum disorder implicates four candidate genes. Hum Genet 2015;134:1055-68.

23. Çetin İ, Tezdiğ İ, Tarakçioğlu MC, et al. Do Low Serum UCH-L1 and TDP-43 Levels Indicate Disturbed Ubiquitin-Proteosome System in Autism Spectrum Disorder? Noro Psikiyatr Ars 2017;54:267-71.

24. Careaga M, Hansen RL, Hertz-Piccotto I, et al. Increased anti-phospholipid antibodies in autism spectrum disorders. Mediators Inflamm 2013;2013:935608.

25. Hu Z, Yang Y, Zhao Y, et al. APOE hypermethylation is associated with autism spectrum disorder in a Chinese population. Exp Ther Med 2018;15:4749-54.

26. Shimamoto C, Ohnishi T, Maekawa M, et al. Functional characterization of FABP3, 5 and 7 gene variants identified in schizophrenia and autism spectrum disorder and mouse behavioral studies. Hum Mol Genet 2015;24:2409.

27. Yamamoto Y, Kida H, Kagawa Y, et al. FABP3 in the Anterior Cingulate Cortex Modulates the Methylation Status of the Glutamic Acid Decarboxylase67 Promoter Region. J Neurosci 2018;38:10411-23.

28. Herbert MR, Russo JP, Yang S, et al. Autism and 
environmental genomics. Neurotoxicology 2006;27:671-84.

29. Mandic-Maravic V, Mitkovic-Voncina M, Pljesa-Ercegovac $M$, et al. Autism Spectrum Disorders and Perinatal Complications-Is Oxidative Stress the Connection? Front Psychiatry 2019;10:675.

30. Benga $\mathrm{O}$, Huber VJ. Brain water channel proteins in health and disease. Mol Aspects Med 2012;33:562-78.

31. Duffney LJ, Zhong P, Wei J, et al. Autism-like Deficits in Shank3-Deficient Mice Are Rescued by Targeting Actin Regulators. Cell Rep 2015;11:1400-13.

32. Zhang L, Huang CC, Dai Y, et al. Symptom improvement in children with autism spectrum disorder following bumetanide administration is associated with decreased GABA/glutamate ratios. Transl Psychiatry 2020;10:9.

33. Roohi J, Montagna C, Tegay DH, et al. Disruption of contactin 4 in three subjects with autism spectrum disorder. J Med Genet 2009;46:176-82.

34. Yoo HJ, Kim K, Kim IH, et al. Whole exome sequencing for a patient with Rubinstein-Taybi syndrome reveals de novo variants besides an overt CREBBP mutation. Int $\mathrm{J}$ Mol Sci 2015;16:5697-713.

Cite this article as: Meng W, Huan Y, Gao Y. Urinary proteome profiling for children with autism using dataindependent acquisition proteomics. Transl Pediatr 2021;10(7):1765-1778. doi: 10.21037/tp-21-193
35. McFadden K, Minshew NJ. Evidence for dysregulation of axonal growth and guidance in the etiology of ASD. Front Hum Neurosci 2013;7:671.

36. Krueger DD, Brose N. Evidence for a common endocannabinoid-related pathomechanism in autism spectrum disorders. Neuron 2013;78:408-10.

37. Zamberletti E, Gabaglio M, Parolaro D. The Endocannabinoid System and Autism Spectrum Disorders: Insights from Animal Models. Int J Mol Sci 2017;18:1916.

38. Zhou J, Parada LF. PTEN signaling in autism spectrum disorders. Curr Opin Neurobiol 2012;22:873-9.

39. Guang S, Pang N, Deng X, et al. Synaptopathology Involved in Autism Spectrum Disorder. Front Cell Neurosci 2018;12:470.

40. Ashwood P. Differential T Cell Levels of Tumor Necrosis Factor Receptor-II in Children with Autism. Front Psychiatry 2018;9:543.

41. Parikshak NN, Swarup V, Belgard TG, et al. Genomewide changes in lncRNA, splicing, and regional gene expression patterns in autism. Nature 2016;540:423-7. 


\section{Supplementary}

Table S1 The composition of age and gender in the ASD and HC group

\begin{tabular}{|c|c|c|}
\hline ID & Gender & Age (years) \\
\hline \multicolumn{3}{|c|}{ ASD $(n=18)$} \\
\hline ASD1 & Male & 5 \\
\hline ASD2 & Male & 5 \\
\hline ASD3 & Male & 7 \\
\hline ASD4 & Female & 4 \\
\hline ASD5 & Male & 3 \\
\hline ASD6 & Male & 4 \\
\hline ASD7 & Male & 3 \\
\hline ASD8 & Male & 7 \\
\hline ASD9 & Female & 4 \\
\hline ASD10 & Male & 4 \\
\hline ASD11 & Male & 6 \\
\hline ASD12 & Male & 7 \\
\hline ASD13 & Male & 6 \\
\hline ASD14 & Male & 4 \\
\hline ASD15 & Male & 8 \\
\hline ASD16 & Female & 4 \\
\hline ASD17 & Male & 5 \\
\hline ASD18 & Male & 4 \\
\hline \multicolumn{3}{|l|}{$\mathrm{HC}(\mathrm{n}=6)$} \\
\hline $\mathrm{HC} 1$ & Male & 6 \\
\hline $\mathrm{HC} 2$ & Male & 5 \\
\hline $\mathrm{HC} 3$ & Male & 5 \\
\hline $\mathrm{HC} 4$ & Male & 3 \\
\hline HC5 & Male & 5 \\
\hline HC6 & Male & 5 \\
\hline
\end{tabular}

ASD, autism spectrum disorder; $\mathrm{HC}$, healthy control.
Table S2 The variable isolation window of the DIA method

\begin{tabular}{|c|c|c|c|c|}
\hline $\mathrm{m} / \mathrm{z}$ & $z$ & t start (min) & t stop (min) & Isolation window $(\mathrm{m} / \mathrm{z}$ \\
\hline 368.5 & 2 & 0 & 90 & 37 \\
\hline 398 & 2 & 0 & 90 & 22 \\
\hline 418.5 & 2 & 0 & 90 & 19 \\
\hline 439 & 2 & 0 & 90 & 22 \\
\hline 458.5 & 2 & 0 & 90 & 17 \\
\hline 474 & 2 & 0 & 90 & 14 \\
\hline 488.5 & 2 & 0 & 90 & 15 \\
\hline 503 & 2 & 0 & 90 & 14 \\
\hline 518 & 2 & 0 & 90 & 16 \\
\hline 534.5 & 2 & 0 & 90 & 17 \\
\hline 549.5 & 2 & 0 & 90 & 13 \\
\hline 562.5 & 2 & 0 & 90 & 13 \\
\hline 576 & 2 & 0 & 90 & 14 \\
\hline 591 & 2 & 0 & 90 & 16 \\
\hline 607.5 & 2 & 0 & 90 & 17 \\
\hline 623 & 2 & 0 & 90 & 14 \\
\hline 637 & 2 & 0 & 90 & 14 \\
\hline 651.5 & 2 & 0 & 90 & 15 \\
\hline 667.5 & 2 & 0 & 90 & 17 \\
\hline 685.5 & 2 & 0 & 90 & 19 \\
\hline 704 & 2 & 0 & 90 & 18 \\
\hline 721.5 & 2 & 0 & 90 & 17 \\
\hline 737.5 & 2 & 0 & 90 & 15 \\
\hline 753.5 & 2 & 0 & 90 & 17 \\
\hline 771 & 2 & 0 & 90 & 18 \\
\hline 789.5 & 2 & 0 & 90 & 19 \\
\hline 808 & 2 & 0 & 90 & 18 \\
\hline 828.5 & 2 & 0 & 90 & 23 \\
\hline 851.5 & 2 & 0 & 90 & 23 \\
\hline 874.5 & 2 & 0 & 90 & 23 \\
\hline 900.5 & 2 & 0 & 90 & 29 \\
\hline 932.5 & 2 & 0 & 90 & 35 \\
\hline 969 & 2 & 0 & 90 & 38 \\
\hline 1013.5 & 2 & 0 & 90 & 51 \\
\hline 1073.5 & 2 & 0 & 90 & 69 \\
\hline 1253.5 & 2 & 0 & 90 & 291 \\
\hline
\end{tabular}

m/z, mass-to-charge ratio; DIA, data-independent acquisition. 
Table S3 All biological processes were enriched in this study

\begin{tabular}{|c|c|c|}
\hline Term & $-\log (P$ value $)$ & Proteins \\
\hline Viral budding via host ESCRT complex & 16.161 & $\begin{array}{l}\text { Q9Y3E7, Q9BY43, Q96EY5, Q9UN37, Q7LBR1, Q8WV92, Q99816, } \\
\text { Q8WUM4, O43633, O75351, Q9HD42 }\end{array}$ \\
\hline Multivesicular body assembly & 14.347 & $\begin{array}{l}\text { Q9Y3E7, Q9BY43, Q96EY5, Q9UN37, Q7LBR1, Q9BRG1, Q99816, } \\
\text { Q8WUM4, O43633, O75351, Q9HD42 }\end{array}$ \\
\hline Cell separation after cytokinesis & 12.886 & $\begin{array}{l}\text { Q9Y3E7, Q9BY43, Q9UN37, Q7LBR1, Q8WV92, Q8WUM4, } \\
\text { O43633, O75351, Q9HD42 }\end{array}$ \\
\hline Nucleus organization & 9.538 & $\begin{array}{l}\text { Q9Y3E7, Q9BY43, Q9UN37, Q7LBR1, Q8WUM4, O43633, O75351, } \\
\text { Q9HD42 }\end{array}$ \\
\hline Mitotic metaphase plate congression & 8.377 & $\begin{array}{l}\text { Q9Y3E7, Q9BY43, Q9UN37, Q7LBR1, Q8WUM4, O43633, O75351, } \\
\text { Q9HD42 }\end{array}$ \\
\hline regulation of mitotic spindle assembly & 7.638 & Q9Y3E7 Q7LBR1 Q8WUM4 O43633 O75351 Q9HD42 \\
\hline positive regulation of exosomal secretion & 7.469 & Q9UN37 O00560 Q99816 Q8WUM4 O43633 O75351 \\
\hline viral life cycle & 7.310 & Q9Y3E7 Q9BY43 Q9UN37 Q99816 Q8WUM4 O43633 O75351 \\
\hline protein transport & 7.252 & $\begin{array}{l}\text { Q16348 Q9UN37 Q96EY5 Q8IX04 O43633 O75351 P51148 P50897 } \\
\text { Q9Y3E7 O00161 Q7LBR1 P61204 P62834 Q99816 Q8WUM4 } \\
\text { Q9HD42 }\end{array}$ \\
\hline regulation of centrosome duplication & 6.886 & Q9Y3E7 Q7LBR1 Q8WUM4 O43633 O75351 Q9HD42 \\
\hline endosomal transport & 6.569 & $\begin{array}{l}\text { Q9Y3E7 Q9BY43 Q9UN37 Q9GZM7 Q9BRG1 Q99816 O43633 } \\
\text { O75351 }\end{array}$ \\
\hline ESCRT III complex disassembly & 6.420 & Q9UN37 Q7LBR1 O43633 O75351 Q9HD42 \\
\hline positive regulation of viral release from host cell & 6.222 & Q9Y3E7 Q9UN37 Q99816 O43633 O75351 \\
\hline autophagy & 5.523 & $\begin{array}{l}\text { Q9H0E2 Q9Y3E7 Q9BY43 Q96EY5 Q9UN37 Q9BRG1 Q99816 } \\
\text { O43633 O75351 }\end{array}$ \\
\hline vacuolar transport & 3.824 & Q9BY43 Q7LBR1 O43633 Q9HD42 \\
\hline $\begin{array}{l}\text { ubiquitin-dependent protein catabolic process } \\
\text { via the multivesicular body sorting pathway }\end{array}$ & 3.824 & Q96EY5 Q9UN37 Q99816 O75351 \\
\hline $\begin{array}{l}\text { ubiquitin-independent protein catabolic process } \\
\text { via the multivesicular body sorting pathway }\end{array}$ & 3.357 & Q9UN37 Q8WUM4 O75351 \\
\hline regulation of viral process & 3.187 & Q9Y3E7 O43633 O75351 \\
\hline positive regulation of viral process & 3.187 & Q96EY5 Q99816 O75351 \\
\hline Ras protein signal transduction & 2.921 & P46109 P62070 O00560 P62873 P01111 113 \\
\hline protein folding & 2.886 & Q8NBS9 P63096 P62879 P02511 P08754 P62873 P14314 \\
\hline small GTPase mediated signal transduction & 2.886 & P63000 P61204 P62070 P62834 P51148 P36405 P60953 P01111 \\
\hline negative regulation of blood coagulation & 2.553 & P02749 P02649 P07204 \\
\hline protein polymerization & 2.481 & Q9Y3E7 Q9BY43 O43633 \\
\hline cell adhesion & 2.444 & $\begin{array}{l}\text { Q8IWV2 P21926 Q9HBB8 P63000 P10586 Q9GZM7 P24821 } \\
\text { P39060 Q9Y6N7 Q14254 }\end{array}$ \\
\hline $\begin{array}{l}\text { proteolysis involved in cellular protein catabolic } \\
\text { process }\end{array}$ & 2.398 & P07711 Q9GZM7 Q9H3G5 Q99538 \\
\hline axon guidance & 2.367 & P15311 Q8IWV2 P63000 O14786 Q9Y6N7 P01111 \\
\hline microvillus assembly & 2.252 & P15311 P62834 P61225 \\
\hline protein homooligomerization & 2.174 & Q9BY43 Q9NZN3 O43633 P02511 Q9H223 P27105 \\
\hline blood coagulation & 2.108 & P08758 P05160 P63000 Q9NZN3 P07204 P60953 \\
\hline epithelial cell differentiation & 1.959 & Q9H0E2 O00526 Q9UBD6 P21796 \\
\hline positive regulation of viral life cycle & 1.886 & Q9UN37 075351 \\
\hline $\begin{array}{l}\text { positive regulation of substrate adhesion- } \\
\text { dependent cell spreading }\end{array}$ & 1.721 & P46109 P63000 P60953 \\
\hline ephrin receptor signaling pathway & 1.699 & P63000 O00560 Q92542 P60953 \\
\hline regulation of extracellular exosome assembly & 1.699 & Q9UN37 075351 \\
\hline $\begin{array}{l}\text { regulation of viral budding via host ESCRT } \\
\text { complex }\end{array}$ & 1.699 & Q99816 Q8WUM4 \\
\hline $\begin{array}{l}\text { positive regulation of viral budding via host } \\
\text { ESCRT complex }\end{array}$ & 1.699 & Q9UN37 Q99816 \\
\hline late endosomal microautophagy & 1.699 & Q96EY5 Q99816 \\
\hline chemical synaptic transmission & 1.658 & P10586 O60939 O00560 P09543 P50897 Q14254 \\
\hline pinocytosis & 1.585 & P50897 Q9H223 \\
\hline $\begin{array}{l}\text { positive regulation of extracellular exosome } \\
\text { assembly }\end{array}$ & 1.585 & O00560 Q8WUM4 \\
\hline cellular response to glucagon stimulus & 1.538 & Q9BY43 P02649 P10912 \\
\hline negative regulation of neuron death & 1.538 & P63092 P62879 P62873 \\
\hline cell division & 1.523 & P63096 Q9UN37 Q7LBR1 Q99816 P08754 P60953 Q9HD42 \\
\hline platelet degranulation & 1.495 & P01033 Q13103 P21926 P02749 \\
\hline $\begin{array}{l}\text { establishment or maintenance of apical/basal cell } \\
\text { polarity }\end{array}$ & 1.481 & P15311 P60953 \\
\hline cellular protein modification process & 1.481 & P61088 O00462 Q99816 Q81X04 \\
\hline receptor internalization & 1.481 & P15311 P21926 P10912 \\
\hline regulation of macroautophagy & 1.456 & P09936 O75348 P36543 \\
\hline vacuole organization & 1.409 & Q9UN37 075351 \\
\hline hair follicle placode formation & 1.409 & Q9UN37 O75351 \\
\hline viral release from host cell & 1.409 & P63092 P60953 \\
\hline membrane invagination & 1.409 & Q9BY43 O43633 \\
\hline platelet activation & 1.377 & P21926 P63000 P61225 P62873 \\
\hline substantia nigra development & 1.377 & P09936 P09543 P60953 \\
\hline membrane budding & 1.337 & P15311 Q9HBB8 \\
\hline regulation of microvillus length & 1.337 & Q9BY43 Q9UN37 \\
\hline cellular response to catecholamine stimulus & 1.337 & P63092 P62873 \\
\hline
\end{tabular}

ESCRT, endosomal sorting complex required for transport; GTPase, guanosine triphosphate hydrolase. 